\title{
Application of a mass consistent flow model to study the $\mathrm{CO}_{2}$ mass balance of forests
}

\author{
Elisa Canepa $^{\mathrm{a}, \mathrm{b}}$, Emilia Georgieva ${ }^{\mathrm{c}}$, Giovanni Manca ${ }^{\mathrm{d}}$, Christian Feigenwinter ${ }^{\mathrm{e}, \mathrm{f}}$ \\ ${ }^{a}$ CNR-INFM-CNISM, Department of Physics, University of Genova, Via Dodecaneso 33, 16146 Genova, Italy \\ ${ }^{b}$ CNR-ISMAR, via De Marini 6, 16149 Genova, Italy \\ ${ }^{c}$ Institute of Geophysics, Bulgarian Academy of Sciences, Sofia Bulgaria \\ ${ }^{\mathrm{d}}$ European Commission, JRQ Institute for Environment and Sustainability, Climate Change Unit, Ispra Italy \\ ${ }^{e}$ Gembloux Agricultural University, Physique des Biosystèmes, Gembloux Belgium \\ ${ }^{f}$ Institute of Meteorology, Climatology and Remote Sensing, University of Basel Switzerland
}

\begin{abstract}
The reconstruction of the wind field is one of the main issues in the mass conservation approach for calculation of $\mathrm{CO}_{2}$ advection in forest ecosystems and still remains a challenging problem. In the current study, we present an advancement of this approach: the use of a mass consistent flow model (WINDS) which takes into account measured wind data and simulates the 3-D flow field, while imposing air mass conservation in the control volume. We apply the WINDS model to calculate half hourly mean total advective flux terms at the arboEurope-IP site of Renon (Bozen/Bolzano Autonomous Province), in Northern Italy. The data used refer to six time periods of one day representing three different meteorological conditions observed during the ADVEX campaign from April to September 2005. Current results are compared with results obtained in two other studies for the same time periods. One of these studies is based on the mass conservation approach as well, but applies only interpolations to reconstruct the wind field; the other study makes use of tilt correction (sectorwise planar fit method) for the vertical wind component. In the present study, the effect of the wind field reconstruction method on the estimation of the advective fluxes is discussed. The possibility of using reduced input wind data (i.e. number of towers) for WINDS is also investigated. The results suggest that the representativeness of wind tower measurements is of primary importance for estimating $\mathrm{CO}_{2}$ advection terms and their uncertainty in complex terrain.
\end{abstract}

\section{Keywords}

Forest ecosystems; Carbon balance; ADVEX; Complex terrain; Mass-conservation; Diagnostic; Wind Model; Advection

\section{Introduction}

Forest ecosystems play an important role in global carbon cycle. Carbon sequestration or release can be quantified by Net Ecosystem Exchange (NEE) of $\mathrm{CO}_{2}$ between forests and atmosphere. At present, NEE is commonly assessed through microme-teorological measurements using the Eddy Covariance (EC) technique. The EC technique relies on a simplified version of the $\mathrm{CO}_{2}$ mass conservation equation: it is based on the measurement of the sum of the turbulent vertical fluxes and changes in storage. Thus, advection terms of the $\mathrm{CO}_{2}$ mass conservation equation are neglected and carbon fluxes might only be roughly estimated, especially during calm and stable nights, when fluxes are strongly underestimated (e.g. Goulden et al., 1996; Paw et al., 2000; Massman and Lee, 2002).

Two different approaches have been discussed in the literature for treating night-time $\mathrm{CO}_{2}$ flux underestimation (Aubinet, 2008): (i) the "filtering approach", most often based on the value of the friction velocity (e.g. Goulden et al., 1996; Suyker et al., 2005; Moureaux et al., 2006; Zhao et al., 2006); and (ii) the "correction approach", based on a direct estimation of all the $\mathrm{CO}_{2}$ balance terms, including the advection terms (e.g. Aubinet et al., 2003, 2005; Feigenwinter et al., 2004; Staebler and Fitzjarrald, 2004; Marcolla et al., 2005; Sun et al., 2007; Yi et al., 2008; Montagnani et al., 2009).

In this study, an improvement to the Montagnani et al. (2009) correction approach is presented. As in Montagnani et al. (2009), the methodology is based on the non-simplified $\mathrm{CO}_{2}$ balance equation, but we concentrate on the assessment of the advection terms. 
Direct estimation of advection terms requires an extensive experimental set-up (several towers equipped with sonic anemometers and many $\mathrm{CO}_{2}$ sampling points), so it was rarely applied. Furthermore, experimental campaigns are in any case not able to achieve the spatial coverage for comprehensive estimates. We believe that appropriate atmospheric boundary layer models could help to solve this problem (Sogachev et al., 2004; Klaassen and Sogachev, 2006; Sun et al., 2006a; Sun et al., 2006b; Sogachev et al., 2008).

One of the challenges in the calculation of advection terms is the velocity field estimation. The studies of Vickers and Mahrt (2006) and Heinesch et al. (2007) imply that tilt correction algorithms for the vertical wind velocity component might still be incomplete and that the mass continuity approach, though difficult to apply, might be the best method to overcome some of the problems. Vickers and Mahrt (2006) computed the mean vertical motion (perpendicular to the terrain) from mass continuity using the horizontal divergence estimated from a network of sonic anemometers. However, they found that the magnitude of the divergence depends on the spatial scale over which the horizontal gradient is calculated. This shortcoming could be overcome with the use of a proper wind field model, which imposes local mass conservation conditions (Ratto et al., 1994).

The present study describes as a test case the application of WINDS (Georgieva et al., 2003), a mass-consistent flow model, in the methodology for the calculation of half hourly averaged advective flux terms, presented in Montagnani et al. (2009). We use data from the ADVEX campaign at the CarboEurope-IP site of Renon (Bozen/Bolzano Autonomous Province), in Northern Italy (Fig. 1, top). A detailed description of the flux measurement system is given by Feigenwinter et al. (2008).

Fig. 1. The experimental set-up of the ADVEX Renon site; $A, B, C, D$, and $M$ indicate the tower positions. Topographic levels (top): the square represents the bottom of the WINDS simulation domain $\left(240 \times 240 \mathrm{~m}^{2}\right)$. The control volume - light grey box - over the local topography (bottom, from Montagnani et al., 2009): the dark grey area represents the bottom of the WINDS simulation domain.
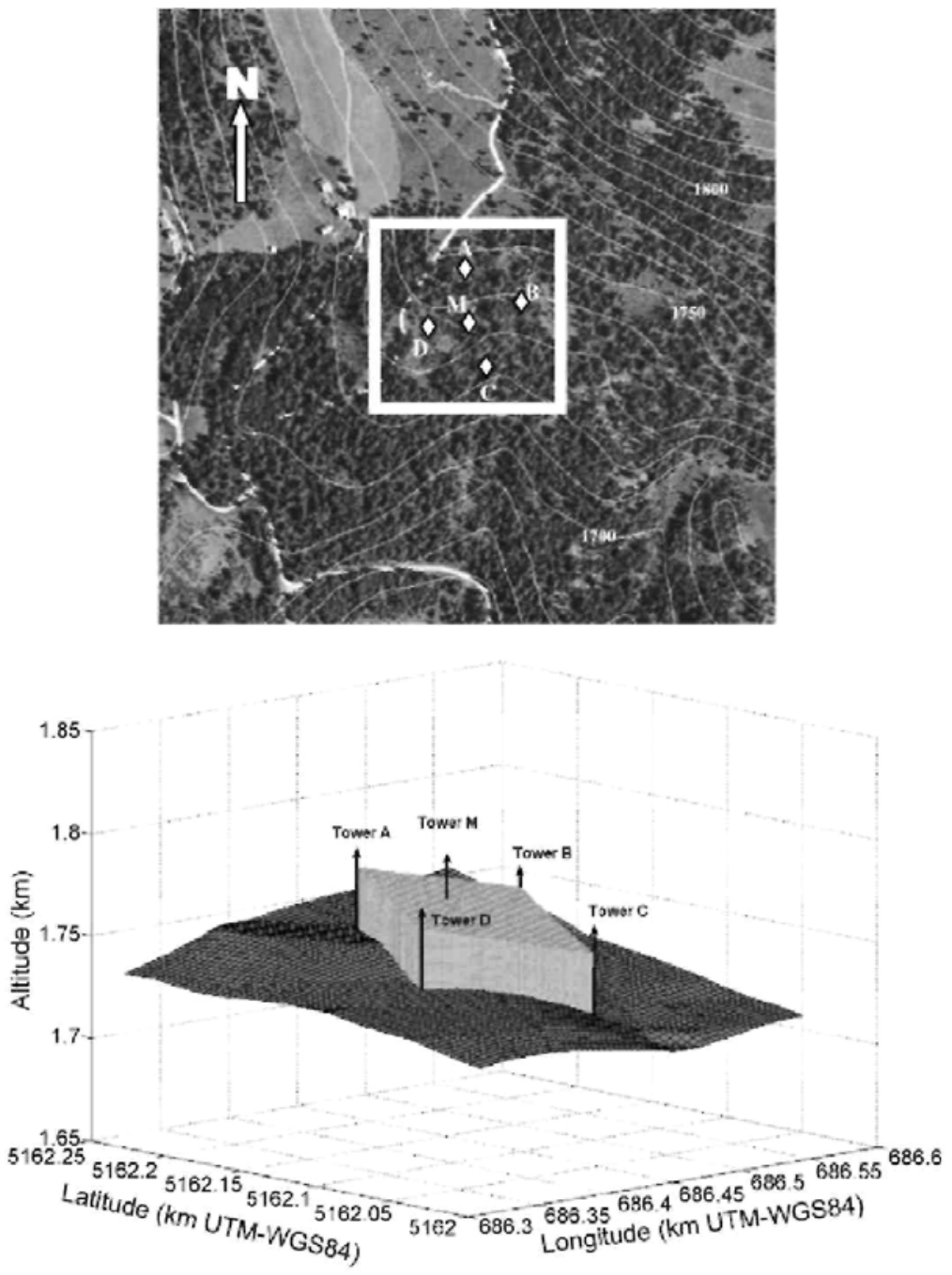
The theoretical framework is explained in detail in Montagnani et al. (2009). Here only, an outline of the methodology is given in order to highlight the new approach in simulating wind fields and achieving mass conservation in the control volume. In fact, the main goal of this study is to propose an approach to physically improve the air mass conservation in the calculation of the wind field in the control volume, which in Montagnani et al. (2009) is achieved in a purely numerical manner, and to investigate the effects it might have on the estimation of advective flux terms.

Our results are compared with the results obtained by both Montagnani et al. (2009) and Feigenwinter et al. (2010) for the same time intervals of the observations at the site of Renon. Theoretical differences between the latter formulation and the present one are discussed in Section 4.1.

A further implication of the WINDS model use concerns the possibility to simulate the 3-D wind fields in the computation domain with data from reduced number of towers, this issue is investigated in Section 4.2.

\section{Theoretical background}

\subsection{Conservation equations}

From the instantaneous transport and diffusion equation for the $\mathrm{CO}_{2}$ concentration expressed as mole density, $n_{\mathrm{c}}$, neglecting the molecular diffusion term and after Reynolds averaging one can obtain the mean transport and diffusion equation:

$$
\bar{\chi}=\frac{\partial \bar{n}_{c}}{\partial t}+\vec{\nabla} \cdot\left(\bar{n}_{c} \overline{\vec{u}}\right)+\vec{\nabla} \cdot\left(\overrightarrow{n_{c}^{\prime} \overrightarrow{u^{\prime}}}\right)
$$

where $\chi$ represents the rate of change of mole density with time $t$ due to the presence of sources and/or sinks, $\vec{\nabla}$ is the divergence operator $\vec{\nabla}=\left(\vec{i} \frac{\partial}{\partial x}+\vec{j} \frac{\partial}{\partial y}+\vec{k} \frac{\partial}{\partial z}\right)$ - with $\vec{i}, \vec{j}, \vec{k}$ being unitary vectors for the Cartesian coordinates with eastward as $\mathrm{x}$, northward as $\mathrm{y}$, and upward normal to the geopotential surface as $z$ directions -and $\vec{u}$ is the instantaneous wind velocity vector - with wind components $\vec{u}(\mathrm{u}, v, \mathrm{w})$ respectively, the overbars indicate time averaged quantities and primes indicate fluctuations around the average of the corresponding quantities.

Eq. (1) is an expression for the scalar mass conservation at a fixed point. In practice we are interested in the mass balance in a control volume built over a representative patch of the surface, therefore we integrate Eq. (1) over a control volume $V$ whose lower boundary is the surface under investigation:

$$
\begin{aligned}
& \iiint_{V} \bar{\chi} d V= \iiint_{V} \frac{\partial \bar{n}_{c}}{\partial t} d V+\iiint_{V} \vec{\nabla} \cdot\left(\bar{n}_{C} \overline{\vec{u}}\right) d V+\iiint_{V} \vec{\nabla} \\
& \cdot\left(\overrightarrow{n_{c}^{\prime} \vec{u}^{\prime}}\right) d V
\end{aligned}
$$

The $\mathrm{CO}_{2}$ conservation equation is sometimes expressed in terms of mass mixing ratio (e.g., Paw et al., 2000; Massman and Lee, 2002; Leuning, 2007), since it is a conservative quantity in processes of heat conduction and water vapour diffusion (Kowalski and Serrano-Ortiz, 2007). However, we deal with the $\mathrm{CO}_{2}$ conservation formulation in terms of $\mathrm{CO}_{2}$ density, as used in the FLUXNET community (e.g., see Heinesch et al., 2007), in order to make directly comparable our formulation with the FLUXNET $\mathrm{CO}_{2}$ conservation equation commonly applied. The latter one is:

$$
\begin{aligned}
\mathrm{NEE}= & \int_{0}^{h_{\mathrm{cv}}} \frac{1}{V_{\mathrm{m}}}\left[\frac{\partial \bar{c}}{\partial t}\right] d \tilde{z}+\frac{1}{V_{\mathrm{m}}}\left(\tilde{\tilde{w}}^{\prime} \mathcal{C}^{\prime}\right)_{h_{\mathrm{cv}}}+\int_{0}^{h_{\mathrm{cv}}} \frac{1}{V_{\mathrm{m}}} \tilde{\bar{w}}(\tilde{z}) \frac{\partial \bar{c}}{\partial \tilde{z}} d \tilde{z} \\
& +\frac{1}{4 L_{\mathrm{cv}}^{2}} \int_{-L_{\mathrm{cv}}-L_{c v}}^{+L_{\mathrm{cv}}+L_{c y} h_{c y}} \frac{1}{V_{\mathrm{m}}}\left(\overline{\tilde{u}} \frac{\partial \bar{c}}{\partial \tilde{x}}+\overline{\tilde{v}} \frac{\partial \bar{c}}{\partial \tilde{y}}\right) d \tilde{x} d \tilde{y} d \tilde{z}
\end{aligned}
$$

where NEE represents the biological source/sink strength term, $h_{c v}$ is the height of the spatial integration control volume and $\mathrm{L}_{\mathrm{cv}}$ is one half of its lateral extent, $V_{m}$ is the molar volume of dry air, $\mathrm{c}$ is the $\mathrm{CO}_{2}$ molar mixing ratio, $\tilde{u}, \tilde{v}$ and $\tilde{w}$ represent the wind velocity components in the horizontal, on a sloping plane nearly parallel to the surface, $(\tilde{x}, \tilde{y})$ directions, and vertical, normal to the surface, $(\tilde{z})$ direction, respectively. 
Comparing Eq. (2) and Eq. (3) the main assumptions made in the FLUXNET studies on computing $\mathrm{CO}_{2}$ fluxes may be noticed: incompressibility, horizontal homogeneity of the vertical concentration gradient, and omission of horizontal turbulent flux divergence terms. Different authors (e.g. Finnigan, 1999, Paw et al., 2000) underline that these simplifications cannot be assumed in many field conditions (e.g., heterogeneous canopy and/or complex orography). Therefore, we have not applied the above simplifications and we have based our study on Eq. (2). Furthermore, it is to be noticed that we use Cartesian coordinates with vertical component normal to the geopotential surface.

After applying the Gauss theorem, Eq. (2) becomes:

$$
\iiint_{V} \bar{\chi} d V=\iiint_{V} \frac{\partial \bar{n}_{c}}{\partial t} d V+\iint_{I} \bar{n}_{C} \overline{\vec{u}} \cdot d \vec{S}+\iint_{I I I} \overline{n_{C}^{\prime} \overrightarrow{u^{\prime}}} d \vec{S}
$$

where $\mathrm{S}$ is the total surface of the control volume and $d \vec{S}$ is a unit vector pointing outwards from the surfaces of the control volume.

In Eq. (4), $I$ is the NEE of the scalar term; $I I$ is the change in storage term; $I I I$ is the advection term; $I V$ is the turbulent transport term.

Further on, we will focus our attention on the calculation of the advection term solely. We rewrite it in terms of $\mathrm{CO}_{2}$ average dry molar fraction values, $\bar{r}_{c}$, using the product $\bar{n}_{c}=\bar{r}_{c} \bar{n}_{\text {tot }}$, where $\bar{n}_{\text {tot }}$ is the average total mole density of dry air. The advection term III becomes:

$$
\operatorname{Term} \text { III }=\iint_{S} \bar{r}_{c} \bar{n}_{t o t} \overline{\vec{u}} \cdot d \vec{S}
$$

In practice, we only have measurements at a few points in the control volume, so we must add extra information to calculate this term domain wide. Different algorithms have been applied for the reconstruction of the 3-D $\mathrm{CO}_{2}$ molar fraction, $\bar{r}_{c}$, the mole density of dry air, $\bar{n}_{t o t}$, and the wind fields starting from available tower measurements (see Section 3).

However, observational data used for the calculations may have mass conservation problems due to various reasons, like representativeness of measurement points, instrumental errors, improper space discretization procedures, or errors introduced by the interpolation algorithms. Therefore, it should be expected that the mole density of dry air and the wind field may not satisfy the mass conservation accurately. Evidently, before performing $\mathrm{CO}_{2}$ advective flux term computations, air density and wind field have to be corrected for air mass conservation.

A two-step procedure was applied in order to achieve mass conservation - the first step makes use of a mass consistent flow model in the control volume (Section 2.3.3), the simulated 3-D wind components are then used in the second step, where a correction for mass imbalance on the surface of the control volume is performed (Section 2.3.4).

\subsection{The control volume}

As mentioned in Section 2.1, a control volume has to be defined in order to calculate the terms of the transport and diffusion equation for $\mathrm{CO}_{2}$ concentration. The choice of its width and shape is arbitrary, but it must be representative of the ecosystem studied by the EC measurements.

In this study, the control volume (Fig. 1, bottom) is defined as an irregular four-sided volume of about 267030 $\mathrm{m}^{3}$ confined at the bottom by the terrain, laterally by four vertical plane surfaces (each of them is confined by adjacent measurement towers), and at the top by a sloping plane nearly parallel to the underling terrain. The top intersects the A, B, and C towers at a height of $30 \mathrm{~m}$ a.g.l., while D and $\mathrm{M}$ towers are intersected at a height of $29.7 \mathrm{~m}$ and $27.7 \mathrm{~m}$, respectively, due to small scale terrain unevenness. The area enclosed within the four external towers is about $8900 \mathrm{~m}^{2}$, such area is intended to be the projection of the base of the control volume on a plane perpendicular to the local gravity. 
The control volume used here is defined in the same manner as in the study of Montagnani et al. (2009) in order to facilitate comparison with previous results at this site.

As mentioned in Section 2.1, the coordinate system is Cartesian with $\mathrm{x}, \mathrm{y}$, and $z$ axes in the East, North, and geopotential directions, respectively; for numerical calculations, a spatial discretization of $1 \mathrm{~m}$ was used with a mesh of $1 \mathrm{~m}$ both in the vertical and horizontal directions.

Other advection studies define a coordinate system with $x$ in the direction of the mean downslope wind, and $z$ normal to the slope (e.g., Yi et al., 2005; Heinesch et al., 2007), but shortcomings related to tilt corrections are highlighted in the literature (e.g., Vickers and Mahrt, 2006; Sun, 2007). As discussed by Sun (2007), the Cartesian coordinate system is a good choice, since it is independent of time and space, and the buoyancy force is normal to the geopotential. Furthermore, finding a common reference coordinate system for wind observations from multiple sonic anemometers and trace gas observations is essential for calculation of the transport terms in the $\mathrm{CO}_{2}$ budget equation. Since both $\mathrm{CO}_{2}$ concentration and wind are measured on towers with positions related to the Earth, we will use Cartesian coordinates instead of streamline ones.

Finding a reliable reference coordinate system for multiple sonic anemometers relies on accurate alignment of sonic anemometers. The uncertainties involved in the Cartesian coordinate system include the alignment of all the sonics to the local gravity. In the present study, all of them were aligned with local gravity to within about $1^{\circ}$ with the aid of an inclinometer. In any case, variations of the rotation angles from Cartesian coordinates to the streamline coordinates obtained using the planar fit method (Wilczack et al., 2001 ) can vary easily up to several degrees from time to time and from location to location, which are much more than uncertainties in sonic anemometer alignments to local gravity.

\subsection{Procedures to calculate the 3-D fields of the physical quantities of interest in the control volume}

In order to calculate the advection term according to Eq. (5), we need to know the values of the physical quantities of interest - the $\mathrm{CO}_{2}$ dry molar fraction, $\bar{r}_{c}$, the total mole density of dry air, $\bar{n}_{t o t}$, and the wind velocity, $\overline{\vec{u}}$ - for each cell of the control volume.

Half hourly means of the measured variables were used further for the calculations, following both Feigenwinter et al. (2008), where the same data were analysed, and other studies for FLUXNET sites (e.g., Feigenwinter et al., 2004; Aubinet et al., 2005; Heinesch et al., 2007; Turnipseed et al., 2004, Staebler and Fitzjarrald, 2004; Yi et al., 2008).

For the reconstruction of the 3-D fields of the above quantities, starting from the available tower measurements, different methods have been applied as described in detail below.

\subsubsection{The 3-D $\mathrm{CO}_{2}$ dry molar fraction fields}

Data for $\mathrm{CO}_{2}$ dry molar fraction collected at three levels $(1.5 \mathrm{~m}, 6 \mathrm{~m}$, and $30 \mathrm{~m}$ a.g.1.) at each lateral tower were used. Data collected at the $12 \mathrm{~m}$ measurement level were excluded from computations because a leak from the sampling polyethylene tube system was detected (Montagnani et al., 2009).

Vertical profiles of $\bar{r}_{c}$ with $1 \mathrm{~m}$ resolution have been obtained for each half hourly time interval trough a quadratic log-function (Feigenwinter et al., 2004), which fits the observed profiles, of the form:

$$
\ln h=a \ln ^{2}\left(\bar{r}_{c}\right)+b \ln \left(\bar{r}_{c}\right)+c
$$

where $h$ is the height a.g.l., and $a, b, c$ are interpolation model parameters for each half an hour (e.g., Fig. 2). Eq. (6) has been chosen because it was found to best fit the independent high resolution 12 level $\mathrm{CO}_{2}$ profile at tower $\mathrm{B}$, measured by the Lund University Team.

The 3-D $\mathrm{CO}_{2}$ dry molar fraction field was obtained through horizontal interpolation of the vertical profiles. A linear interpolation based on a Delaunay triangulation of the data was applied. The Delaunay triangulation was computed using the Quickhull algorithm (Barber et al., 1996). Each triangle was a plain surface and the vertices of each triangle were points of the four vertical profiles calculated by the procedure described above. 


\subsubsection{The 3-D fields of total mole density of dry air}

The 3-D fields of total mole density of dry air, $\bar{n}_{\text {tot }}$, for each half hourly time interval were obtained from the measured values of air temperature, air pressure, and $\mathrm{H}_{2} \mathrm{O}$ molar fraction inside the control volume. However, temperature and $\mathrm{H}_{2} \mathrm{O}$ molar fraction were measured at different spatial points with respect to pressure temperature and $\mathrm{H}_{2} \mathrm{O}$ molar fraction data were available at three levels, $1.5 \mathrm{~m}, 6 \mathrm{~m}$, and $30 \mathrm{~m}$ a.g.l. for each lateral tower, while pressure data were collected only at the base of the central tower.

In order to calculate the air pressure values at the same points where air temperature and $\mathrm{H}_{2} \mathrm{O}$ molar fraction were measured, a vertical profile for the pressure was constructed, for each half hourly time interval, extrapolating surface data in the vertical with a linear decrease of $10 \mathrm{~Pa} \mathrm{~m}^{-1}$. This pressure profile was then assumed to be valid for the entire control volume.

Fig. 2. Vertical profiles of measured and interpolated half-hour averaged $\bar{r}_{\mathrm{c}}\left(\mathrm{CO}_{2}\right.$ dry molar fraction) for July 11, doy 192, at 24:00 LST (strong northerly flow); solid, dotted, dashed and dash-dotted lines represent the interpolated values at towers $A, B, C$, and $D$, respectively, while black circles, open circles, black triangles, and open triangles represent the measured values.

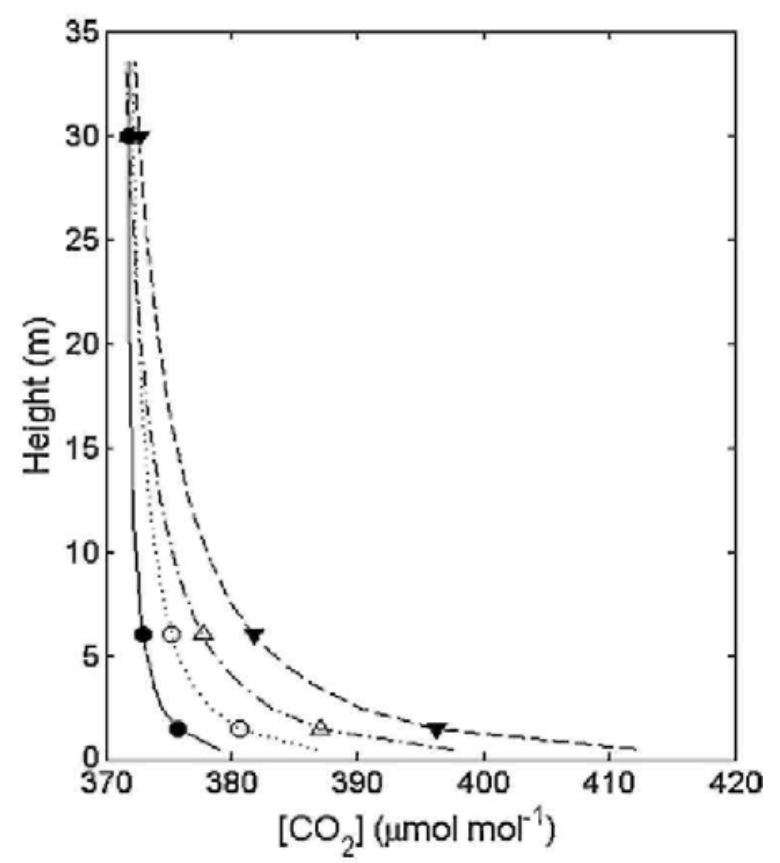

As a next step, the total mole density of dry air, $\bar{n}_{t o t}$, was calculated for each measurement point by the following equation based on the Dalton's law of partial pressures:

$$
\bar{n}_{t o t}=\frac{\bar{p}_{\mathrm{a}}-\bar{e}}{R \bar{T}_{\mathrm{a}}}
$$

where $\bar{p}_{\mathrm{a}}$ is the air pressure, $R$ is the universal gas constant, $\bar{T}_{\mathrm{a}}$ is the air temperature, $\bar{e}=\bar{p}_{\mathrm{a}} \bar{r}_{\mathrm{w} \text { moist }}$ is the water vapour pressure, and $\bar{r}_{\mathrm{w} \text { moist }}$ is the water molar fraction.

The vertical profile of $\bar{n}_{\text {tot }}$ at each lateral tower was calculated with a resolution of $1 \mathrm{~m}$ using Eq. (6).

For the horizontal interpolation of $\bar{n}_{\mathrm{tot}}$, the same procedure as for the $\mathrm{CO}_{2}$ dry molar fraction, $\bar{r}_{c}$, has been applied. 


\subsubsection{The 3-D wind fields}

In order to obtain the 3-D half hourly averaged wind fields a code, WINDS (Wind-field Interpolation by NonDivergent Schemes), has been applied. WINDS (Georgieva et al., 2003) is a diagnostic mass-consistent model (Ratto et al., 1994) designed to simulate the air flow over complex terrain taking into account available observations within the model domain. The application of this code is the novelty with respect to the methodology for $\mathrm{CO}_{2}$ flux estimation presented recently in Montagnani et al. (2009) and Montagnani et al. (2010).

The calculation of the 3-D wind field is achieved by a two-step procedure:

1) "initial" wind field, $\vec{u}^{0}\left(\bar{u}^{0}, \bar{v}^{0}, \bar{w}^{0}\right)$, is constructed over the modelling domain through some kind of vertical and horizontal interpolation of available wind data. This "first guess" normally does not obey the mass conservation;

2) adjustment procedure based on a variational approach (Sasaki (1970), Sherman (1978)) is applied so that the resulting (or "final") wind field, $\overline{\vec{u}}(u, v, w)$, satisfies mass conservation and is closest as much as possible to the initial field.

The mathematical formalism leads to an equation for the so-called Lagrange multiplier $\lambda=\lambda(\mathrm{x}, \mathrm{y}, \mathrm{z})$, which determines the modifications to the initial wind components:

$$
\begin{aligned}
& \frac{\partial^{2} \lambda}{\partial x^{2}}+\frac{\partial^{2} \lambda}{\partial y^{2}}+\left(\frac{\alpha_{1}}{\alpha_{2}}\right)^{2} \frac{\partial^{2} \lambda}{\partial z^{2}}=-2 \alpha_{1}^{2}\left(\frac{\partial \bar{u}^{0}}{\partial x}+\frac{\partial \bar{\nu}^{0}}{\partial y}+\frac{\partial \bar{w}^{0}}{\partial z}\right) \\
& \bar{u}=\bar{u}^{0}+\frac{1}{2 \alpha_{1}^{2}} \frac{\partial \lambda}{\partial x} ; \quad \bar{v}=\bar{v}^{0}+\frac{1}{2 \alpha_{1}^{2}} \frac{\partial \lambda}{\partial y} ; \quad \bar{w}=\bar{w}^{0}+\frac{1}{2 \alpha_{2}^{2}} \frac{\partial \lambda}{\partial z}
\end{aligned}
$$

The values of $\lambda$ result from any initial errors in the derivation of the initial field (initial divergence) and due to terrain influences on the flow. The two parameters $\alpha 1$ and $\alpha_{2}$, known as Gaussian precision modules, govern the extent of the flow modification in the horizontal and vertical direction and are thus related to the atmospheric stratification.

The boundary conditions for solving Eq. (8), expressed by:

$$
\lambda \delta(\overline{\vec{u}}) \cdot \vec{n}=0 \text { on } \Sigma
$$

where $\delta(\overrightarrow{\vec{u}})$ is the adjustment of the wind field, $\vec{n}$ is the unit vector normal to the boundary surface of the modelling domain, and $\sum$ is the surface of the modelling domain, are interpreted following Sherman (1978).

For open or "flow-through" boundaries, i.e. the observed normal velocity component through the boundary is different from zero $\left(\overrightarrow{\vec{u}}^{0} \cdot \vec{n} \neq 0\right)$, the adopted condition is:

$$
\lambda=0
$$

In general, the normal derivative of $\lambda$ is different from zero and as results from Equation (9) an adjustment of the observed velocity component normal to the boundary may occur. This boundary condition is used on the lateral vertical boundaries of the domain.

For closed or "no-flow-through" boundaries, i.e. the observed normal velocity component through the boundary is zero $\left(\overrightarrow{\vec{u}}^{0} \cdot \vec{n}=0\right)$, the adopted condition is:

$$
\delta(\vec{u}) \cdot \vec{n}=0
$$

The condition (12) implies no adjustment in the normal velocity component, thus $\overline{\vec{u}} \cdot \vec{n}=0$. This boundary condition is used both at the bottom (earth surface) and at the top of the domain. 
The following characteristics of the code should be highlighted as relevant to the model application in this study:

- the incompressible form of the continuity equation is used as a constraint for adjusting the flow field - see RHS of Eq. (8); the density is thus assumed constant in the modelling domain;

- the code is written in conformai coordinates, which are terrain-following just above the terrain and flat at the top of the simulation domain; this allows better representation of the terrain and higher vertical grid resolution close to it.

The modelling domain for WINDS (Fig. 1) has been defined larger than the control volume. The extensions of the former are $240 \mathrm{~m}$ in both horizontal directions, while in the vertical it reaches up to $500 \mathrm{~m}$ a.g.l. The horizontal discretization is $4 \mathrm{~m}$, the vertical resolution is variable, starting from $0.5 \mathrm{~m}$ near the ground and going up to $160 \mathrm{~m}$ near the top. The model domain has been chosen in a way to include all measurement towers and to avoid numerical border effects on the control volume wind field, especially as far as the vertical component is concerned.

For the construction of the initial wind field, a vertical interpolation of towers measurements as proposed by Feigen-winter et al. (2008) has been applied. Then, at each conformai level, the wind components are linearly interpolated to obtain the initial 3D field.

The output of WINDS has then to be brought to the grid of the control volume that has a resolution of $1 \mathrm{~m}$ along both the horizontal and vertical directions. For this purpose, a postprocessing of WINDS fields has been applied, using linear interpolation.

\subsubsection{Air mass imbalance correction}

The wind field obtained using the procedure described in Section 2.3.3 is mass-consistent only with a certain approximation. Two main reasons might be responsible for this. On the one hand -the WINDS numerical approximations, on the other hand, the loss of mass conservation due to the interpolation between the grid of the WINDS domain and the grid of the control volume. Furthermore, pressure and wind fields are decoupled from each other in the simulations.

Thus, even after applying the code WINDS, air mass imbalance might still be present in the control volume and a procedure to reduce it should be applied. In this study, the same correction procedure as in Montagnani et al. (2009) has been adopted.

Using the already calculated 3-D fields of air mole density and wind velocity, the deviation from the mass conservation, $\Delta Q$, was numerically estimated for each half hour:

$\Delta Q=\sum_{i} \bar{n}_{\text {tot } i} \bar{u}_{i} \Delta S_{i}$

where $\Delta S_{i}$ are the $1 \mathrm{~m}^{2}$ elementary surface elements of the control volume, $\bar{n}_{\text {tot } i}$ is the average air density for each surface element, and $\bar{u}_{i}$ is the average wind velocity component perpendicular to each surface element. Positive values of $\Delta Q$, mean air transport out of the control volume, while negative $\Delta Q$ values refer to air flux into the control volume.

In order to perform a numerical adjustment of the air mass imbalance, each term $\bar{n}_{\text {tot } i} \bar{u}_{i} \cdot \Delta S_{i}$ (named elementary flux) is modified with a correction factor, cf, so that in case of $\Delta Q<0$, it implies the decrease of negative and the increase of positive elementary fluxes, and vice versa.

The correction factor is formed by the ratio of the mass conservation imbalance in the whole control volume, $\Delta Q$, and the overall sum of the absolute values of the elementary fluxes:

$\mathrm{cf}=\frac{\Delta Q}{\sum_{i}\left|\bar{n}_{t o t i} \bar{u}_{i} \Delta S_{i}\right|}$

and the correction below was performed: 
- if $\bar{n}_{\text {tot } i} \bar{u}_{i} \Delta S_{i}>0$ then $\bar{n}_{\text {tot } i} \bar{u}_{i} \Delta S_{i} \rightarrow(1-c f) \bar{n}_{\text {toti }} \bar{u}_{i} \Delta S_{i}$

- if $\bar{n}_{\text {tot } i} \bar{u}_{i} \Delta S_{i}<0$ then $\bar{n}_{\text {tot } i} \bar{u}_{i} \Delta S_{i} \rightarrow(1+c f) \bar{n}_{\text {tot } i} \bar{u}_{i} \Delta S_{i}$

This numerical correction guarantees the air mass conservation in the control volume, that is to say, $\Delta Q$ approximates zero. It is noticeable that this correction procedure allows the average total mole density of dry air to be inhomogeneous. The corrected values for the product of the air density and the wind are then used for estimation of the $\mathrm{CO}_{2}$ advective flux terms on the surface of the control volume, Eq. (5).

High absolute values of the $c f$ factor mean that air mass conservation is not satisfactorily achieved in the control volume using the proposed procedure. Therefore, the $c f$ factor can be considered as a component of the uncertainty of the calculated products of the air density and the wind. We are aware that this correction factor is a numerical artifice, but $\Delta \mathrm{Q}$ must approximate zero, otherwise the proposed advection calculation method is not applicable. From the previous considerations, one can infer that $c f$ should be minimized.

\subsection{Advection term calculation}

In the following, we briefly outline the framework of the proposed procedure as summarized in the Fig. 3 flowchart.

The application of the interpolation procedures described in the previous sections lead to a 3-D reconstruction of the physical quantities of interest in the control volume with a spatial discretization of $1 \mathrm{~m}$. Calculation of the advection term, following Eq. (5), requires only the use of the respective quantities for each volume cell $\left(1 \mathrm{~m}^{3}\right)$ sited along each discrete surface element $(\vec{S})$ of the control volume. According to the micrometeorological convention, a negative value is assigned to the fluxes entering the volume and a positive value is given to those leaving it.

Summing the individual advective flux terms entering or exiting from the 4 lateral surfaces and the top of the control volume, a total advective flux term relative to the entire control volume is obtained. In order to obtain the unitary advective flux term, the total advective flux term is divided by the area covered by the control volume.

We highlight that we do not treat separately vertical and horizontal advective flux terms - e.g., as Feigenwinter et al. (2008) and the majority of the works about advection terms -but we calculate their sum directly. The uncertainties involved in the separate calculation of vertical and horizontal advection are related, among others, also to terrain slope estimation. This error, according to Sun (2007), should be less than several degrees. With the approach proposed here, this source of uncertainty is avoided.

\section{Description of the measurement site and the study periods}

The ADVEX extensive measurement campaign was performed during 133 days from May to September 2005 at the CarboEurope Renon/Ritten site (e.g., Feigenwinter et al., 2008 ; Montagnani et al., 2009). The site is situated at $1735 \mathrm{~m}$ a.s.l. in the Italian Alps $12 \mathrm{~km} \mathrm{NNE}$ of Bolzano (AltoAdige, Italy) and is operated by the Forest Service and the Agency of the Environment of the Autonomous Province of Bolzano (APB). The standard instrumentation of the Renon flux tower, $\mathrm{M}$, was supplemented with a set of four additional $30 \mathrm{~m}$ towers (A, B, $\mathrm{C}, \mathrm{D})$ equipped so as to capture vertical profiles of wind velocities, $\mathrm{CO}_{2}$ and temperature as well as horizontal transects of $\mathrm{CO}_{2}$ and temperature in order to evaluate the exchange processes of $\mathrm{CO}_{2}$ in the soil-vegetationatmosphere control volume with a high spatial resolution.

The Renon area is influenced by an alpine, windy and humid climate. Its topography is characterized by an alpine slope with a mean value of about $11^{\circ}$ in a N-S direction. The unevenly aged coniferous forest is heterogeneous with gaps between groups of older and younger trees with heights between $20 \mathrm{~m}$ and $30 \mathrm{~m}$. The main forest species is spruce (Picea abies (L.) Karst., $85 \%$ in number) followed by cembran pine (Pinus cembra L, 12\%) and larch (Larix decidua Mill., 3\%). About $60 \mathrm{~m}$ upslope to the north of the main tower, M, a pasture disturbs the fetch in the main night-time wind direction. Ground vegetation varies widely from sparse to dense. Being unevenly forested and featuring a highly complex topography with small-scale variations, this research site displays very challenging conditions for studying carbon fluxes, comprising advection terms. 
Fig. 3. Flowchart for the computation of total advective flux.

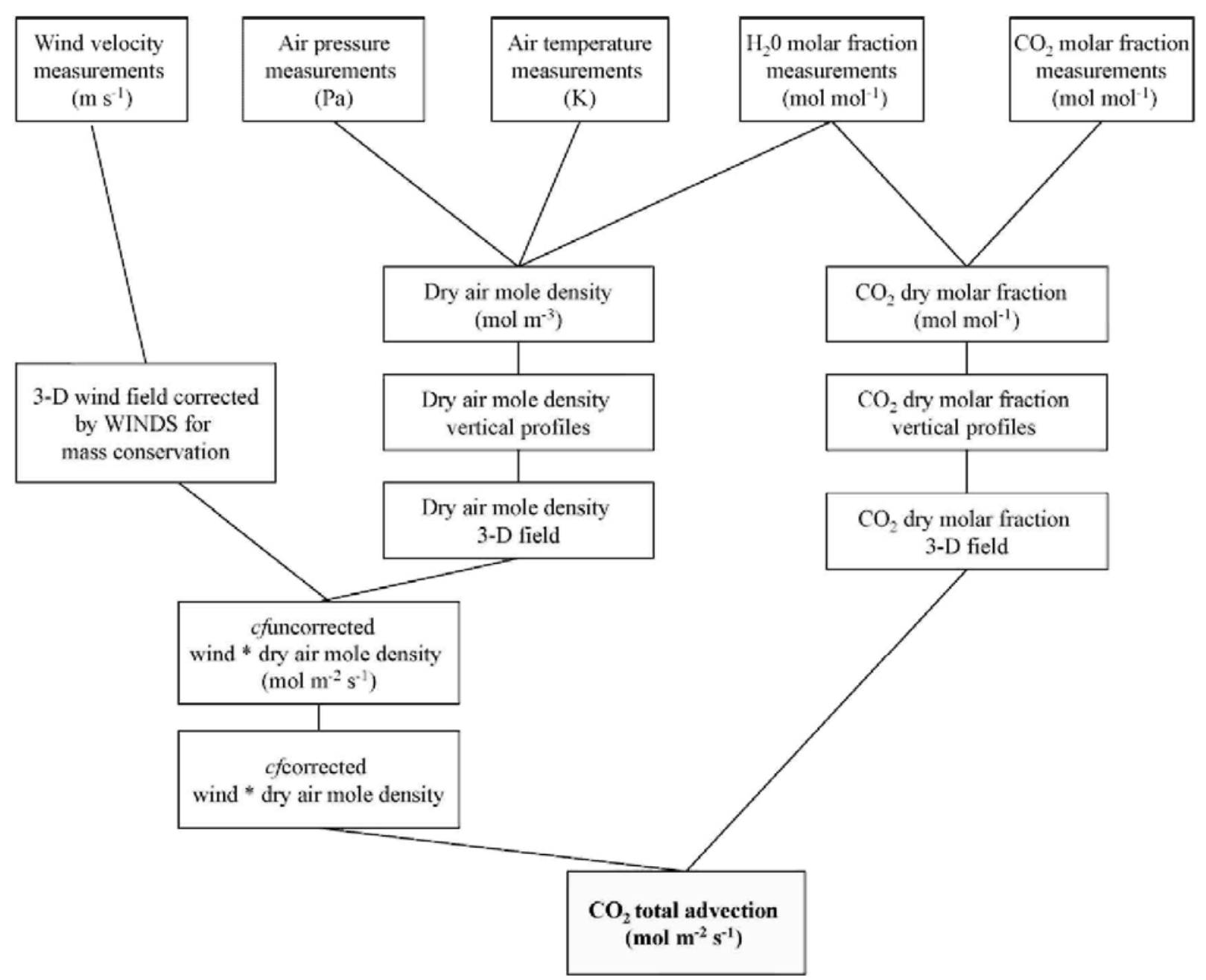

The meteorological conditions during the experimental campaign were dominated by a very persistent local wind circulation with upslope S-SW winds during the day and downslope N-NW winds during the night. This situation was typical for about $75 \%$ of the measurement period. The very similar distribution of the wind directions above and inside the canopy during these local circulations suggests that the canopy layer is most of the time well coupled with the surface roughness layer above the canopy. The rest time of the period was dominated by synoptic-driven circulations: either by "Tramontana", a cold and strong wind, which blows consistently for a few days from the north also during daytime and penetrates into the canopy, or by persistent moderate warm winds from S to SW, also blowing during the night. See also Feigenwinter et al. (2010) for a more detailed description of the meteorological conditions.

As a test case, we studied six different 24-hour time periods, all these periods were studied in both Montagnani et al. (2009) and Feigenwinter et al. (2008) as well:

1 ) two periods characterised by "Tramontana", day of year (doy) 183-184 and 192-193;

2) two periods characterised by southerly wind, doy 205-206 and 207-208;

3) two periods characterised by the local slope wind system, resulting in downslope wind (near northerly) during the night, and upslope wind (near southerly) during the day, doy 209-210 and 210-211.

In order to cover the complete life history of a diurnal cycle, the selected time periods start at 11:30 LST (local standard time) of the first day and end at 11:30 LST of the second day, except the 192-193 period, that starts and ends half hour earlier due to lack of data for the last half hour. The periods have been selected as 
representative for the three typical flow conditions described above and for the completeness of the data time series.

Fig. 4. Dry air mass imbalance in the control volume, comparison between the absolute values of the cffactors for the six considered periods using WINDS (initialized with A, B, C, and D towers) and using only interpolations as Montagnani et al.(2009).
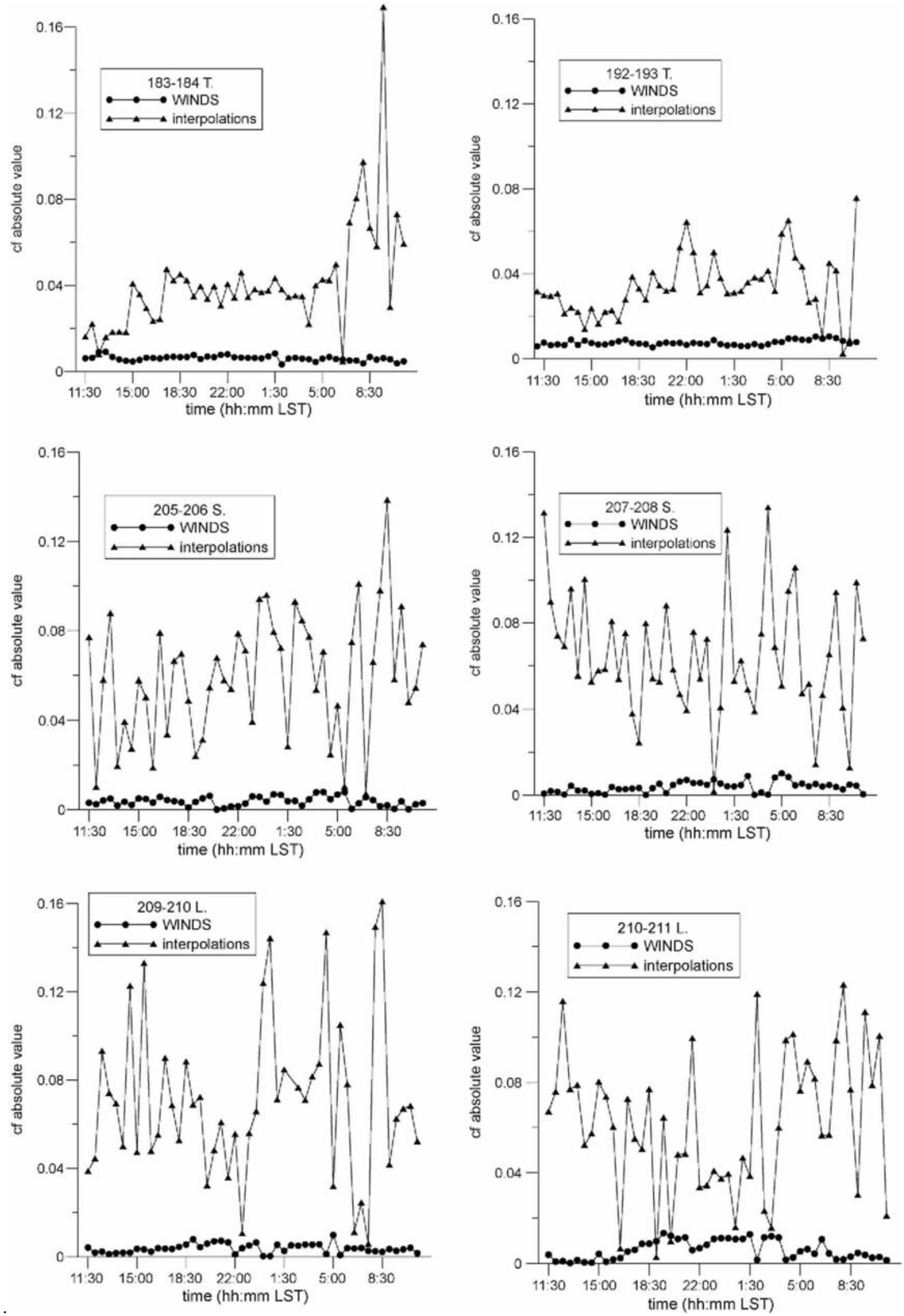


\section{Results and discussion}

\subsection{WINDS initialization using data from all ADVEX towers}

4.1.1. Effect of WINDS on the air mass imbalance in the control volume Fig. 4 depicts the temporal behaviour of the absolute values of the $c f$ factors for the six considered periods using WINDS and using interpolations as in Montagnani et al. (2009). It can be noticed that nearly all $c f$ absolute values, and thus their sum, are reduced to a great extent when applying the model WINDS. On the contrary, the spreading of the $c f$ absolute values, as well as their sum, is greater in the case of interpolations. Therefore, by using the correction factor as an indicator, we conclude that WINDS outperforms simple interpolations for maintaining dry air mass conservation in the control volume.

We are aware that applying the WINDS model air mass conservation can be satisfied to a great extent, although the wind distribution inside the domain can be inaccurate. We believe, however, that mass consistency is a necessary, even if not sufficient, condition to achieve an accurate wind field reconstruction starting from measurements.

Fig. 5 shows a comparison between Montagnani et al. (2009) interpolated wind profiles and WINDS profiles for the $\mathrm{u}, \mathrm{v}$, and $\mathrm{w}$ wind components for the A, B, C, and D tower positions, doy 193, 00:30 LST. We selected this half-hour time interval because it shows relevant differences among the $\mathrm{CO}_{2}$ advective flux terms obtained using the Montagnani et al. (2009) and the present methodology (see Section 4.1.2). Fig. 5 demonstrates differences in the wind profiles at various towers, which suggest that they are representative for very local conditions (see also Section 4.1.2). The adjustments performed by WINDS in order to attain mass-consistency are also evident in the profiles.

4.1.2. Calculated advection terms using data from all ADVEX towers Fig. 6 shows the diurnal variation of the half-hourly averaged $\mathrm{CO}_{2}$ total advective flux terms (sum of horizontal and vertical advection terms) simulated using WINDS following the methodology described in this paper in comparison to the modelled values as in Feigenwinter et al. (2010) and in Montagnani et al. (2009). The night-time (from 21:30 to 3:30 LST) averaged total $\mathrm{CO}_{2}$ advection terms and the relative standard deviations are reported in Table 1.

The present methodology differs from that used by Feigenwinter et al. (2010) both from a theoretical point of view and from a computational one. On the theoretical point of view, Feigenwinter et al. (2010) assume air incompressibility and horizontally homogeneous $\mathrm{CO}_{2}$ concentration gradient, while the present methodology is fully 3-D and incompressibility is not assumed. On the computational point of view, the Feigenwinter et al. (2010) approach differs from the present methodology in that (see also Table 2): (i) horizontal and vertical advective flux terms are treated separately, their sum is estimated directly (see also Section 2.4); (ii) in order to deal with vertical wind components at the towers the sectorwise planar fit method is applied, Cartesian coordinates with vertical axis normal to the geopotential surface are used; (iii) it is necessary to know the values of the physical quantities of interest in the whole control volume, on the control volume boundaries only; (iv) a modified linear interpolation scheme is used to derive vertical profiles from the measured $\mathrm{CO}_{2}$, a quadratic logfunction - Equation (6) - is applied; (v) a modified linear interpolation scheme is used to derive vertical profiles from the measured horizontal wind velocities and horizontal bilinear interpolation is applied, wind fields in the control volume are reconstructed using the WINDS model and then the products of the wind and the air density are corrected in order to achieve mass conservation (see Sections 2.3.3 and 2.3.4).

Table 1 Night-time (from 21:30 to 3:30 LST) averaged total $\mathrm{CO}_{2}$ advection $\pm S D$ (Standard Deviation) for the six study periods calculated by the present method in comparison to the calculated values as in Feigenwinter et al. (2008) and in Montagnani et al. (2009).

\begin{tabular}{|c|c|c|c|c|c|c|}
\hline \multirow[b]{3}{*}{ DOY } & \multicolumn{6}{|c|}{ Night-time (from 21:30 to 3:30 LST) averaged total $\mathrm{CO}_{2}$ advection $\pm \mathrm{SD}\left(\mu \mathrm{mol} \mathrm{m}^{-2} \mathrm{~s}^{-1}\right)$} \\
\hline & "Tramontana" & & Southerly wind & & Local slope w & \\
\hline & $183-184$ & $192-193$ & $205-206$ & $207-208$ & $209-210$ & $210-211$ \\
\hline Present study & $40.3 \pm 10.3$ & $40.4 \pm 11.4$ & $4.3 \pm 3.4$ & $2.6 \pm 4.3$ & $13.5 \pm 9.5$ & $-3.8 \pm 8.1$ \\
\hline $\begin{array}{l}\text { Feigenwinter et al. } \\
(2008)\end{array}$ & $34.6 \pm 16.1$ & $40.6 \pm 10.2$ & $5.1 \pm 6.0$ & $4.7 \pm 4.2$ & $14.7 \pm 9.0$ & $0.9 \pm 14.8$ \\
\hline Montagnani et al. (2009) & $6.8 \pm 4.0$ & $6.8 \pm 6.6$ & $0.3 \pm 3.3$ & $3.8 \pm 4.1$ & $11.7 \pm 2.7$ & $13.8 \pm 2.9$ \\
\hline
\end{tabular}


Table 2 Summary of computational differences between the methodology by Feigenwinter et al. (2010) and the present approach (see the text for details); FHA and FVA are horizontal and vertical advective flux terms, respectively.

\begin{tabular}{lll}
\hline & Feigenwinter et al. (2010) & This study \\
\hline Advective fluxes (FHA, FVA) & Treated separately & Sum directly estimated \\
Vertical wind component & Sectorwise planar fit & Cartesian coords normal to geopotential surface \\
Required spatial resolution of & As dense as possible in the whole & As dense as possible on the control volume boundary \\
measurements & control volume & only \\
Vertical [CO2]-profiles & Modified linear interpolation & Log-square function \\
Wind field & Modified linear interpolation for vertical & WINDS, mass conservation, density corrected \\
& profiles, horizontal bilinear interpolation \\
\hline
\end{tabular}

Fig. 5. Comparison between Montagnani et al. (2009) interpolated wind profiles (solid line) and WINDS profiles (dashed line) for the $u, v$, and $w$ wind components for the A, B, C, and D tower positions, doy 193, 00:30 LST (time step 27).
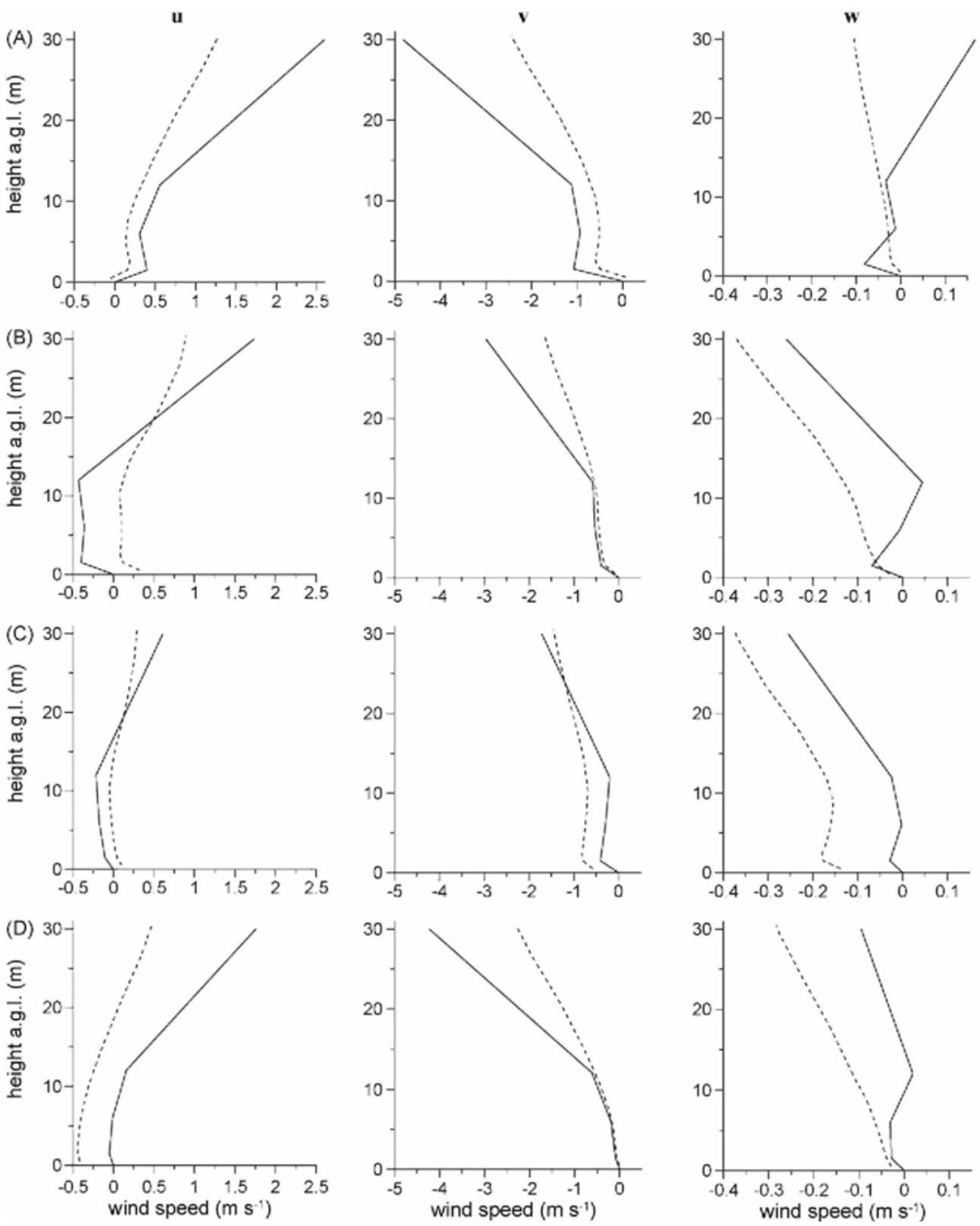
Fig. 6. Diurnal variation of the calculated half-hourly averaged $\mathrm{CO}_{2}$ total advecitive fluxes: present methodology (thick line), Feigenwinter et al. (2008) methodology (thin line), and Montagnani et al. (2009) methodology (dashed line); time is expressed as hh:mm LST; "Tramontana" periods (T.) - left, southerly wind periods (S.) - middle, local slope wind periods (L.) - right.
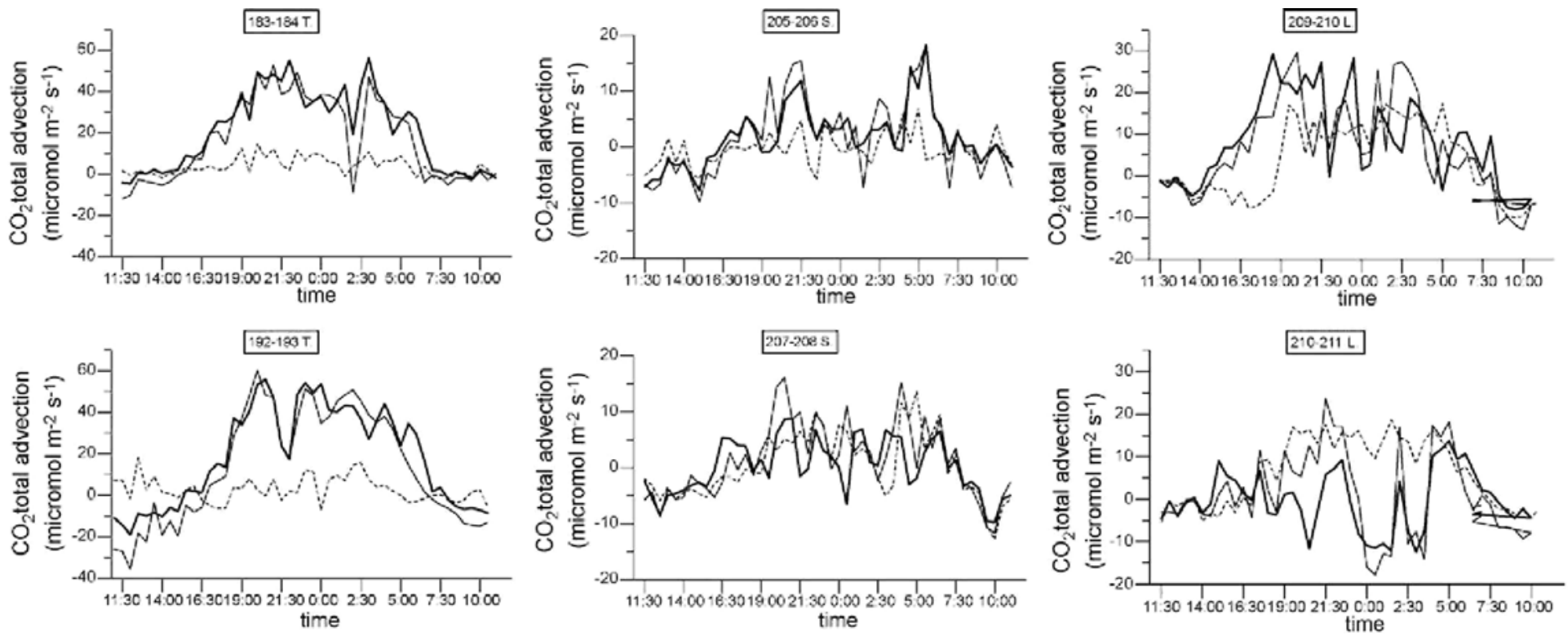

We further stress here that the difference between the Montagnani et al. (2009) and the present methodology is the approach in simulating wind fields and achieving mass conservation in the control volume: in the first case, interpolations are used to reconstruct the 3-D wind fields in the control volume from tower measurements and the correction factor $c f$ is applied in order to numerically correct the air mass imbalance in the control volume; in the second case, the WINDS mass-consistent model is used to reconstruct the 3-D wind fields in the control volume from tower measurements and the correction factor $c f$ is applied in order to numerically correct only the residual air mass imbalance in the control volume.

We did not perform a quantitative uncertainty analysis for the advection terms. In any case, we believe that uncertainties in the $\mathrm{CO}_{2}$ total advective flux terms calculated with the present approach can arise mainly from: the calibration of WINDS in order to reconstruct 3D wind fields (see also Section 4.2), the introduction of the correction factor $c f$ and the $\mathrm{CO}_{2}$ data interpolation method. As far as the reconstruction of 3-D wind fields is concerned, one has to notice that wind measurements inside the canopy can be severely influenced by very local conditions (e.g., Poggi and Katul, 2008), therefore their representativeness can be very limited in space.

Furthermore, Queck and Bernhofer (2010) highlight the necessity to solve for systematic overestimation for wind measurements in the canopy, caused by placing the sensors in free spaces of the canopy. Concerning the reconstruction of the 3-D CO 2 fields, it is to note that the spatial resolution of the $\mathrm{CO}_{2}$ measurement system was not sufficient to take small-scale (less than $100 \mathrm{~m}$ ) field heterogeneities into account (Aubinet et al., 2010). This suggest that the interpolated 3-D $\mathrm{CO}_{2}$ field could be unrepresentative of the presence of a micro-scale variability due to "hot spots" (Rodeghiero and Cescatti, 2008), that is to say small zones with large concentrations. In particular, at the Renon site, the highest mean $\mathrm{CO}_{2}$ concentrations are observed at tower $\mathrm{C}$, where the stand is characterized by the densest vegetation and the highest trees (Feigenwinter et al., 2010).

Apart from a limited number of data (that can be found mainly in the 209-210 local slope wind period), the behaviour of the present results is similar to the one obtained by Feigenwinter et al. (2010), while the results by Montagnani et al. (2009) show major differences both for the 210-211 local slope wind period and for the two "Tramontana" periods. Therefore, we believe the differences among results are mainly imputable to the different methodologies which are used to reconstruct wind field in the control volume, starting from tower wind measurements and to the action of the $c f$ correction factor.

The application of correction factor results in smoothing of peak values of the product of air density and wind, the bigger the $c f$ correction factor, the bigger the smoothing effect (see Section 2.3.4). Therefore, the Montagnani et al. (2009) method provides smoothed $\mathrm{CO}_{2}$ elementary advective fluxes with respect to the present method, if 
peak values for the product of the air density and the wind are present. This is the main reason for the differences noted in the results for the "Tramontana" periods.

Looking at the results for the southerly wind periods, the total nocturnal average advection calculated using the method proposed here is smaller than the same quantity calculated by Feigenwinter et al. (2010). In fact, results obtained by Feigenwinter et al. (2010) for the southerly wind period showed the highest vertical advective flux terms, it was due to comparatively large negative vertical velocity component during the night, probably resulting from incomplete planar fit algorithm for this situation. If planar fit is applied only to southerly wind conditions, the vertical advective flux terms may nearly vanish (Feigenwinter et al., 2010).

The standard deviation (SD) gives information about the spreading of the calculated half-hourly $\mathrm{CO}_{2}$ total advective flux terms during each night-time period. Such spreading is wide. As discussed by Finnigan (2000), Kelvin-Helmholtz $(\mathrm{KH})$ waves, produced in the canopy top region, are propagating into the canopy leading to very substantial scalar fluctuations.

The $\mathrm{CO}_{2}$ total advective flux terms should be smaller than the total ecosystem respiration during night conditions. Rodeghiero and Cescatti (2005) describe an extensive soil respiration measurement campaign performed at the Renon site using 21 sampling points (collars) from spring 2000 to spring 2002 . They found a spatially-averaged maximum values of soil respiration of about $7 \mu \mathrm{mol} \mathrm{m} \mathrm{m}^{-1}$ for a soil temperature at $10 \mathrm{~cm}$ depth of about $10 \div 12{ }^{\circ} \mathrm{C}$, which is about the most elevated temperature for the site. It is reasonable to assume that this elevated soil temperature are reached in summer and, therefore, that a spatially average soil respiration value of about $7 \mu \mathrm{mol} \mathrm{m} \mathrm{m}^{-2} \mathrm{~s}^{-1}$ is reasonable for summer 2005 as well. Soil respiration accounts for between $40 \%$ and $90 \%$ of total ecosystem respiration (e.g., Longdoz et al., 2000). Unfortunately, foliar and woody tissue respiration measurements have never been performed at Renon. But from Lavigne et al. (1997), who studied ecosystem respiration rates at six coniferous BOREAS sites, the sum of respiration of foliage and wood are roughly equal to that of soil. From Montagnani et al. (2009), there is some evidence that at night storage is negligible and turbulent flux, roughly speaking again, is about $3 \mu \mathrm{mol} \mathrm{m} \mathrm{m}^{-2}$. Therefore, we believe that the calculated total advective flux terms for local slope wind and southerlies conditions could be reconcilable with biotic fluxes. On the contrary, the calculated total advective flux terms are evidently not reconcilable with biotic fluxes for Tramontana conditions.

\subsection{Calculated advection terms using a reduced number of towers}

The WINDS model is able to simulate the 3-D wind fields in the computational domain even if the number of measurement input from towers is reduced. In order to investigate the effect of reduced input data on WINDS modelled wind fields, we carried out numerical experiments initializing the model with data from three towers in various arrangements - (i) ABC towers; (ii) ABD towers; (iii) ACD towers; (iv) BCD towers - for three study periods - the "Tramontana" doy 183-184, the southerly wind doy 205-206, the local slope wind doy 209-210.

An analysis of the absolute values of $c f$ correction factors (not shown for sake of brevity) demonstrated that mass-consistency is attained with about the same level of precision both using three towers only and using the complete set of the ADVEX towers.

From Table 3, it can be deduced that the night-time averaged $\mathrm{CO}_{2}$ advective flux term vary greatly with the different tower's arrangement for all three flow conditions. In fact, as already said, wind measurements inside the canopy can be severely influenced by very local effects and this fact limits their spatial representativeness. Therefore, as far as the 3-D wind field reconstruction is concerned, major uncertainties can be attributed to under-representativeness of the tower measurements.

Table 3Night-time (from 21:30 to 3:30 LST) averaged total $\mathrm{CO}_{2}$ advection $\pm S D$ (Standard Deviation) for three study periods calculated by the present method using WINDS initialized with data from: (i) ABC towers; (ii) ABD towers; (iii) ACD towers; (iv) BCD towers.

\begin{tabular}{llll}
\hline & \multicolumn{2}{l}{ Night-time (from 21:30 to 3:30 LST) averaged total $\mathrm{CO}_{2}$ advection $\pm \mathrm{SD}\left(\mu \mathrm{mol} \mathrm{m}^{-2} \mathrm{~s}^{-1}\right)$} \\
\cline { 2 - 4 } WINDS initialization & "Tramontana" 183-184 & Southerly wind 205-206 & Local slope wind 209- \\
& & & $8.5 \pm 7.8$ \\
\hline ABC towers & $45.7 \pm 11.7$ & $-1.1 \pm 2.8$ & $13.9 \pm 8.0$ \\
ABD towers & $18.3 \pm 6.1$ & $8.0 \pm 4.0$ & $2.2 \pm 6.2$ \\
ACD towers & $43.4 \pm 12.2$ & $2.1 \pm 3.0$ & $9.7 \pm 8.6$ \\
BCD towers & $23.5 \pm 5.6$ & $3.3 \pm 4.0$ & \\
\hline
\end{tabular}




\section{Conclusions}

We present the results from the application of a methodology based on mass-consistency in the calculation of half hourly mean $\mathrm{CO}_{2}$ total advective flux terms at the alpine site of Renon. The theoretical framework is based on the setting of the $\mathrm{CO}_{2}$ conservation equation in a control volume, it follows in general the one proposed by Montagnani et al. (2009), but we introduced an advancement in the calculation of the advection terms based on the use of the mass-consistent flow model WINDS in order to construct 3-D wind fields in the computational domain. Even if we highlight that pressure and wind fields are decoupled from each other, WINDS outperforms simple interpolations, as done in Montagnani et al. (2009), for maintaining dry air mass conservation in the control volume.

From a theoretical point of view, the present formulation for the calculation of total advective flux terms differs from the commonly applied ones because it is fully 3-D and incompressibility is not assumed. Furthermore, it makes use of Cartesian coordinate system and it does not deal with vertical and horizontal advective flux terms separately, but it treats their sum.

The present formulation overcomes difficulties related to the determination of the vertical velocity component: in fact, Vickers and Mahrt (2006) highlighted discrepancies between the vertical velocities computed using different tilt correction algorithms. Moreover, the application of the present formulation allows to focus experimental efforts on the control volume boundaries.

The proposed approach has been tested on a data set from the ADVEX campaign at the CarboEurope-IP site of Renon (Bozen/ Bolzano Autonomous Province) in Northern Italy. Our results have been compared with the results reported by Montagnani et al. (2009) and Feigenwinter et al. (2010) for the same test case.

The behaviour of half-hourly averaged $\mathrm{CO}_{2}$ total advective flux terms, simulated by the present approach, is very similar to the one obtained by Feigenwinter et al. (2010); on the contrary, the Montagnani et al. (2009) results show major differences with respect to the two other approaches. Therefore, we believe that the different methodologies which are used to reconstruct wind field in the control volume starting from tower wind measurements and the action of the correction factor for mass conservation are responsible for main differences in the results. For example, during the "Tramontana" periods, the differences in the calculated advective flux terms are mainly due to the smoothing effect of the correction factor for air mass conservation, which values are higher in the approach by Montagnani et al. (2009) than in the one presented here.

It is well known that mass-consistent model results depend critically on the initialization, that is to say on the representativeness of wind input data. To test the effect of reduced number of input data on calculated advective flux terms, simulations were performed initializing WINDS with data from only three towers, selected in various arrangements. The results revealed that $\mathrm{CO}_{2}$ advective flux term values are greatly dependent on the different tower's arrangement. In fact, wind measurements inside the canopy can be severely influenced by very local conditions, limiting their spatial representativeness. Furthermore, as stated by Aubinet et al. (2010), the spatial resolution of the $\mathrm{CO}_{2}$ measurement system as well was not sufficient to take small-scale field heterogeneities into account. Therefore, major uncertainties can be attributed to under-representativeness of the samplings.

In conclusion, despite the fact that working with a consistent mass balance is more theoretically sounded, we do not really believe that a reliable, accurate 3-D wind field - and a consequent estimation of $\mathrm{CO}_{2}$ advective flux terms - can be obtained by the proposed modelling approach given the under-representativeness of the samplings. Major efforts should be devoted, on the one hand, to collect more representative information about forest ecological systems from measurements, on the other hand, to develop effective canopy layer parameterizations in order to support modelling activity.

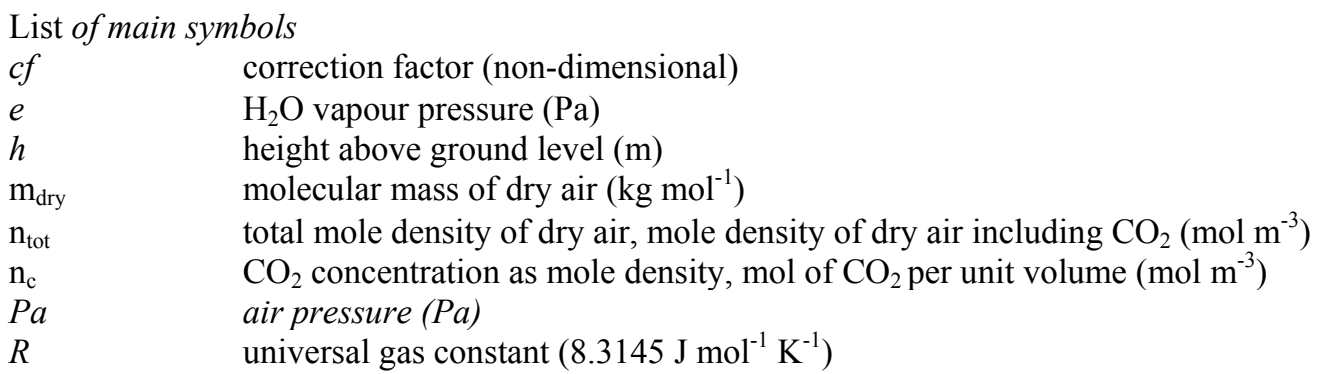




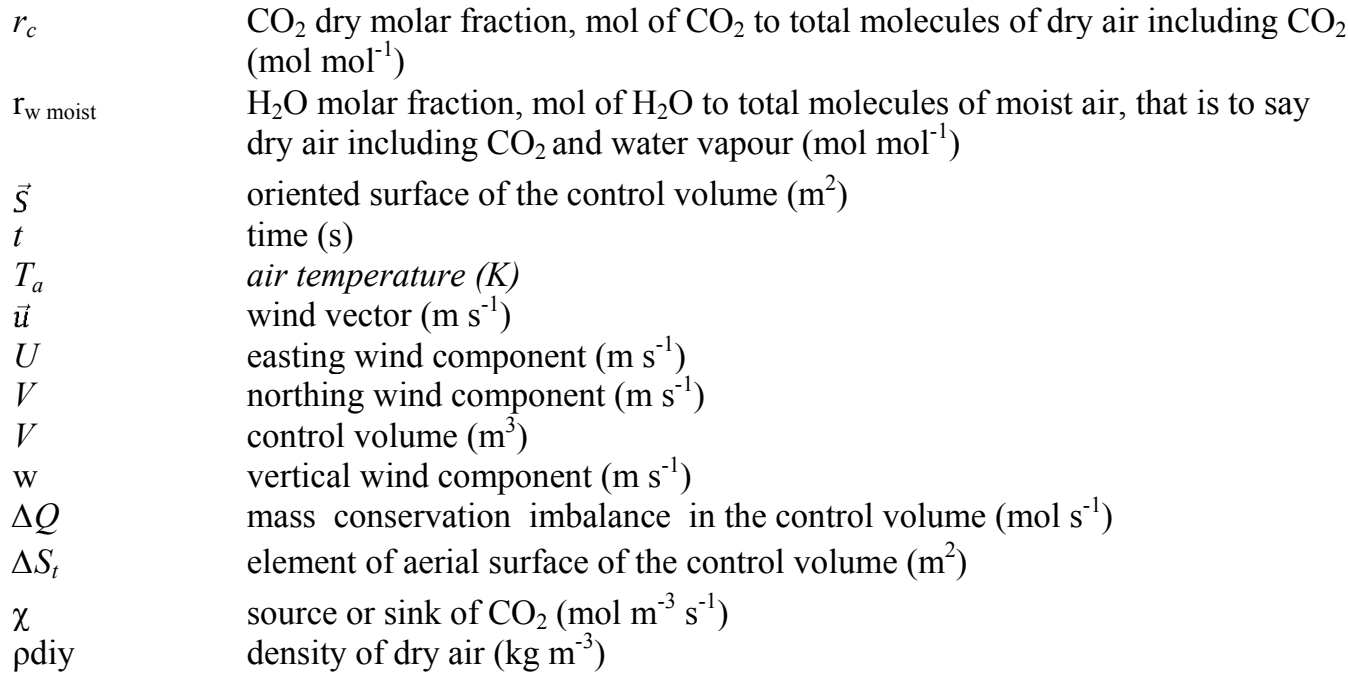

\section{Acknowledgements}

The experimental part of this work was performed in the frame of the CarboEurope Integrated Project of the European Commission (Contract N-GOCE-CT-2003-505572). This work was partially supported by CNR (The Italian National Research Council) within the CNR-CNISM (National Consortium of Italian Universities for the Physics of the Matter) Agreement. CINFAI (National Consortium of Italian Universities for Physics of Atmospheres and Hydrosphere) is gratefully acknowledged to support the activities of the Physics of the Atmosphere Group - Department of Physics - University of Genoa (Italy). Reviewers of the paper are gratefully acknowledged for useful suggestions.

\section{References}

Aubinet, M., Heinesch, B., Yernaux, M., 2003. Horizontal and vertical $\mathrm{CO}_{2}$ advection in a sloping forest. Bound. Layer Meteorol. 108, 397417 .

Aubinet, M., Berbigier, P., Bernhofer, C.H., Cescatti, A., Feigenwinter, C, Granier, A., Grunwald, T.H., Havrankova, K., Heinesch, B., Longdoz, B., Barcolla, B., Mon-tagnani, L, Sedlak, P., 2005. Comparing $\mathrm{CO}_{2}$ storage and advection conditions at night at different Carboeuroflux sites. Bound. Layer Meteorol. 116, 63-94.

Aubinet, M., 2008. Eddy covariance $\mathrm{CO}_{2}$ flux measurements in nocturnal conditions: an analysis of the problem. Ecol. Appl. 18, 1368-1378.

Aubinet, M., Feigenwinter, C, Bernhofer, C, Canepa, E., Heinesch, B., Lindroth, A., Montagnani, L., Rebmann, C, Sedlak, P., Van Gorsel, E., 2010. Direct advection measurements do not help to solve the nighttime $\mathrm{CO}_{2}$ closure problem - evidence from three different forests Agric. Forest Meteorol. 150, 655-664.

Barber, C.B., Dobkin, D.P., Hudanpaa, H.T., 1996. The Quickhull Algorithm for Convex Hulls. ACM Trans. Mathemat. Software 22, 469483.

Feigenwinter, C, Bernhofer, C, Vogt, R., 2004. The influence of advection on the short term $\mathrm{CO}_{2}$-budget in and above forest canopy. Bound Layer Meteorol. 113, 201-224.

Feigenwinter, C, Bernhofer, C, Eichelmann, U., Heinesch, B., Hertel, M., Janous, D., Kolle, O., Lagergren, F., Lindroth, A., Minerbi, S., Moderow, U., Molder, M., Montagnani, L., Queck, R., Rebmann, C, Vestin, P., Yernaux, M., Zeri, M., Ziegler, W., Aubinet, M., 2008. Comparison of horizontal and vertical advective $\mathrm{CO}_{2}$ fluxes at three forest sites. Agric. Forest Meteorol. 148, 12-24.

Feigenwinter, C, Montagnani, L., Aubinet, M., 2010. Plot-scale vertical and horizontal transport of CO2 modified by a persistent slope wind system in and above an alpine forest. Agric. Forest. Meteorol. 150 665-673.

Finnigan, J., 1999. A comment on the paper by Lee (1998): "On micrometeorological observations of surface-air exchange over tall vegetation". Agric. Forest Meteorol. 97, 55-64.

Finnigan, J., 2000. Turbulence in plant canopies. Annu. Rev. Fluid Mech. 32,519-571.

Georgieva, E., Canepa, E., Mazzino, A. Ratto, CF., 2003. WINDS Release 4.2 User's Guide. Department of Physics - University of Genova, Genova, Italy, http:// www.fisica.unige.it/atmosfera/_file/safe_air_II/winds4_2.pdf. 
Goulden, M.L., Munger, J.W., Fan, S.M., Daube, B.C., Wofsy, S.C., 1996. Measurements of carbon sequestration by long-term eddy covariance: Methods and a critical evaluation of accuracy. Glob. Change Biol. 2 (3), 169-182.

Heinesch, B., Yernaux, M, Aubinet, M., 2007. Some methodological questions concerning advection measurements: a case study. Bound. Layer Meteorol. 122, 457-478.

Klaassen, W., Sogachev, A., 2006. Flux footprint simulation downwind of a forest edge. Bound. Layer Meteorol. 121, 459-473.

Kowalski, A.S., Serrano-Ortiz, P., 2007. On the relationship between the eddy covariance, the turbulent flux, and surface exchange for a trace gas such as $\mathrm{CO}_{2}$. Bound. Layer Meteorol. 124, 129-141.

Lavigne, M.B., Ryan, M.G., Anderson, D.E., Baldocchi, D.D., Crill, P.M., Fitzjarrald, D.R., Goulden, M.L., Gower, S.T., Massheder, J.M., McCauhey, J.H., Rayment, M., Striegl, R.G., 1997. Comparing nocturnal eddy covariance measurements to estimates of ecosystem respiration made by scaling chamber measurements. J. Geophys. Res. 102, 28977-28986.

Leuning, R., 2007. The correct form of the Webb, Pearman and Leuning equation for eddy fluxes of trace gases in steady and non-steady state, horizontally homogeneous flows. Bound. Layer Meteorol. 123, 236-267.

Longdoz, B., Yernaux, M., Aubinet, M., 2000. Soil $\mathrm{CO}_{2}$ efflux measurements in a mixed forest: impact of chamber disturbances, spatial variability and seasonal evolution. Glob. Change Biol. 6, 907-917.

Marcolla, B., Cescatti, A., Montagnani, L., Manca, G., Kerschbaumer, G., Minerbi, S., 2005. Importance of advection in the atmospheric CO2 exchanges of an alpine forest. Agric. Forest Meteorol. 130, 193-206.

Massman, W.J., Lee, X., 2002. Eddy covariance flux corrections and uncertainties in long-term studies of carbon and energy exchanges. Agric. Forest Meteorol. 113, 121-144.

Montagnani, L., Manca, G., Canepa, E., Georgieva, E., Acosta, M., Feigenwinter, C, Janous, D., Kerschbaumer, G., Lindroth, A., Minach, L., Minerbi, S., Molder, M., Pavelka, M., Seufert, G., Zeri, M., Ziegler, W., 2009. A new mass conservation approach to the study of CO advection in an alpine forest. J.Geophys. Res. 114, D07306, doi: 10.1029/2008JD010650.

Montagnani, L., Manca, G., Canepa, E., Emilia Georgieva, E., 2010. Assessing the method-specific differences in quantification of CO advection at three forest sites during the ADVEX campaign. Agric. Forest Meteorol. 150, 702-711.

Moureaux, C, Debacq, A., Bodson, B., Heinesch, B., Aubinet, M., 2006. Carbon sequestration by a sugar beet crop. Agric. Forest Meteorol. $139,25-39$

Paw U, K.T., Baldocchi, D., Meyers, T.P., Wilson, K.B., 2000. Correction of eddy-covariance measurements incorporating both advective effects and density fluxes. Bound. Layer Meteorol. 97, 487-511.

Poggi, D., Katul, G.G., 2008. The effect of canopy roughness density on the constitutive components of the dispersive stresses. Exp. Fluids $45,111-121$.

Queck, R., Bernhofer, C, 2010. Constructing wind profiles in forests from limited measurements of wind and vegetation structure. Agric Forest Meteorol. 150, 724-735

Ratto, CF., Festa, R., Romeo, C, Frumento, O.A., Galluzzi, M., 1994. Mass-consistent models for wind fields over complex terrain: the state of the art. Environ. Software 9, 247-268.

Rodeghiero, M., Cescatti, A., 2005. Main determinants of forest soil respiration along an elevation/temperature gradient in the Italian Alps. Glob. Change Biol. 11, 1024-1041.

Rodeghiero, M., Cescatti, A., 2008. Spatial variability and optimal sampling strategy of soil respiration. Forest Ecol. Manag. 255, 106-112.

Sasaki, Y., 1970. Some basic formalism in numerical variational analysis. Monthly Weather Rev. 98, 875-883.

Sherman, C.A., 1978. A mass-consistent model for wind fields over complex terrain. J. Appl. Meteorol. 17, $312-319$.

Sogachev, A., Rannik, U., Vesala, T., 2004. Flux footprints over complex terrain covered by heterogeneous forest. Agric. Forest Meteorol. 127, 143-158.

Sogachev, A., Leclerc, M.Y., Zhang, G., Rannik, U., Vesala, T., 2008. $\mathrm{CO}_{2}$ fluxes near a forest edge: a numerical study. Ecol. Appl. 18, 1454-1469.

Staebler, R.M., Fitzjarrald, D.R., 2004. Observing subcanopy $\mathrm{CO}_{2}$ advection. Agric. Forest Meteorol. 122, $139-156$.

Sun, H., Clark, T.L., Stull, R.B., Black, T.A., 2006. Two-dimensional simulation of airflow and carbon dioxide transport over a forested mountain Part I. Interaction between thermally-forced circulations. Agric. Forest Meteorol. 140, 338-351. 
Sun, H., Clark, T.L., Stull, R.B., Black, T.A., 2006. Two-dimensional simulation of airflow and carbon dioxide transport over a forested mountain Part II. Carbon dioxide budget analysis and advection effects. Agric. Forest Meteorol. 140,352-364.

Sun, J., 2007. Tilt corrections over complex terrain and their implication for CO2 transport. Bound. Layer Meteorol. 124, 143-159.

Sun, J., Burns, S.P., Delany, A.C., Oncley, S.P., Turnipseed, A.A., Stephens, B.B., Lenschow, D.H., LeMone, M.A., Monson, R.K., Dean, E., Anderson, D.E., 2007. CO2 transport over complex terrain. Agric. Forest Meteorol. 145, 1-21.

Suyker, A.E., Verma, S.B., Burba, G.G., Arkebauer, T.J., 2005. Gross primary production and ecosystem respiration of irrigated maize and irrigated soybean during a growing season. Agric. Forest Meteorol. 131, 180-190.

Turnipseed, A.A., Anderson, D.E., Burns, S., Blanken, P.D., Monson, R.K., 2004. Airflows and turbulent flux measurements in mountainous terrain. Part 2: Meso-scale effects. Agric. Forest Meteorol. 125, 187-205.

Vickers, D., Mahrt, L, 2006. Contrasting mean vertical motion from tilt correction methods and mass continuity. Agric. Forest Meteorol. $138,93-103$.

Wilczack, J., Oncley, S.P., Stage, S.A., 2001. Sonic anemometer tilt correction algorithms. Bound. Layer Meteorol. 99, 127-150.

Yi, C, Monson, R.K., Zhai, Z., Andrson, D.E., Lamb, B., Allwine, G., Turnipseed, AA, Burns, S.P., 2005. Modeling and measuring the nocturnal drainage flow in a high-elevation subalpine forest with complex terrain. J. Geophys. Res. 110,1-13.

Yi, C, Anderson, D., Turnipseed, A., Burns, S., Sparks, J., Stannard, D., Monson, R., 2008. The contribution of advective fluxes to net ecosystem exchange in a high-elevation, subalpine forest. Ecol. Appl. 18 (6), 1379-1390.

Zhao, LA, Li, Y.N., Xu, S.X., Zhou, H.K., Gu, S., Yu, G.R., Zhao, X.Q, 2006. Diurnal, seasonal and annual variation in net ecosystem CO 2 exchange of an alpine scrubland on Qinghai-Tibetan plateau. Glob. Change Biol. 12, 1940-1953. 